\title{
A contrarreforma trabalhista e as tendências da precarização do trabalho no Brasil
}

\section{Labor counter-reform and trends in precarious work in Brazil}

Hiago Trindade ${ }^{*}$

Resumo: Neste artigo, realizamos pesquisa documental e revisão de literatura com o objetivo de explicitar as determinações da contrarreforma trabalhista no Brasil e as novas formas de regulação contratuais por ela estabelecidas, com ênfase nos trabalhos intermitente, terceirizado e autônomo. Concluímos indicando que a contrarreforma trabalhista atesta uma mudança histórica no nível de precarização do trabalho no Brasil e, como corolário, na degradação da classe trabalhadora, submetida cada vez mais a situações de pauperização absoluta.

Palavras-chave: Contrarreforma trabalhista. Precarização do trabalho. Brasil.

\begin{abstract}
In this article, we conducted documentary research and literature review with the objective of explaining how determinations of labor counterreform in Brazil and how new forms of contractual control applicable by it, with an emphasis on intermittent, outsourced and autonomous work. We conclude that it will define a labor counterpart after a historical change in the level of precarious work in Brazil and, as a corollary, in the degradation of the working class, which is increasingly subjected to situations of absolute impoverishment.
\end{abstract}

Keywords: Labor counter-reform. Precarious work. Brazil.

Recebido em 20/04/2020. Aceito em 03/03/2021.

\footnotetext{
* Doutor em Serviço Social pela Universidade Federal do Rio de Janeiro. Mestre em Serviço Social (UFRN) Bacharel em Serviço Social ( UERN). Professor do Curso de Serviço Social da Universidade Federal de Campina Grande (UFCG - Campus Sousa).E-mail: hiagolira@hotmail.com
} 


\section{Introdução}

Com este artigo, objetivamos discorrer sobre a contrarreforma trabalhista estabelecida no Brasil (especialmente em 2017), descortinando algumas de suas determinações e, sobretudo, analisando as formas de regulação contratual que se alastram a partir de sua aprovação, a saber: trabalho intermitente, terceirizado e autônomo.

Para atender ao objetivo proposto, realizamos revisão de literatura, por meio da qual estabelecemos diálogo crítico com um conjunto de aportes teóricos fornecidos por autores clássicos e contemporâneos, especialmente aqueles que, inscritos no âmbito da tradição marxista, preocuparam-se em compreender as atuais transformações processadas no mundo do trabalho no Brasil, dentre os quais, poder-se-ia citar: Ianni (1989), Gounet (1999), Fernandes (2005), Filgueiras (2019), Antunes (2018), Abílio (2017).

Realizamos, ainda, pesquisa documental (LAVILLE; DIONNE, 1999). Tal investida se consubstanciou na análise das leis nº 13.429/2017 e no 13.467/2017 - que tratam, respectivamente, da terceirização de atividades finalísticas e da alteração da Consolidação das Leis do Trabalho (CLT). Além das leis supramencionadas, também nos debruçamos sobre alguns documentos importantes para a pesquisa e para o texto em tela, a exemplo do parecer da reforma, elaborado pelo deputado Rogério Marinho (PARECER DA REFORMA, 2017), e dos materiais produzidos pelo Departamento Intersindical de Estatística e Estudos Socioeconômicos (DIEESE, 2017) e pelo Instituto Brasileiro de Geografia e Estatística (IBGE, 2019).

Nessa direção, no âmbito deste texto, partimos do entendimento segundo o qual, na particularidade brasileira, vivemos uma conjuntura cada vez mais regressiva no que tange ao "mundo do trabalho". Assim, diante do contexto de crise e de acirramento da ofensiva neoliberal presente em toda a América Latina, os direitos sociais e trabalhistas - frutos de importantes conquistas históricas da classe trabalhadora - vêm sendo alvo de progressivos desmontes. Nesses tempos, como sugeriu o professor Ricardo Antunes (2018), a precarização do trabalho é regra.

Na verdade, como já expuseram diversos analistas (Cf. dentre outros, BARBOSA, 2008), o mercado de trabalho no Brasil nasce e se estrutura envolto por um elevado grau de precarização. Entre nós, portanto, a precarização é uma regra antiga e seus efeitos sempre ressoaram negativamente para um enorme contingente de trabalhadores. Nesse contexto, se é verdade que as lutas de classe foram responsáveis por materializar um pífio padrão de proteção trabalhista entre nós ${ }^{1}$, também é correto afirmar que, a despeito de as conquistas alcançadas representarem avanços relativamente significativos, as medidas de regulação do trabalho aqui estabelecidas nunca foram capazes de modificar, substancialmente, as péssimas condições e relações de trabalho implementadas desde a abolição do trabalho escravo (TRINDADE, 2020).

Assim, com os sucessivos processos de reestruturação produtiva do capital, observamos a generalização de formas de trabalho precário, desprotegido e desregulamentado, ainda que, muitas vezes, exista um esforço em fazer transparecer uma noção positiva em torno das modalidades de trabalho flexíveis, estas cada vez mais disseminadas no Brasil.

Em seu estudo, Dal Rosso (2017) percebe a flexibilidade para além dos discursos propagandeados por instituições e sujeitos, por meio dos quais o fenômeno costuma estar revestido, única e exclusivamente, por um manto de positividade. Seu esforço teórico, portanto, se inscreve

\footnotetext{
${ }^{1}$ Ao contrário daqueles que advogam a tese de um povo inerte, corroboramos com Octávio Ianni (1989), ao indicar que o Brasil sempre esteve envolto nas lutas travadas por indígenas, mulheres e negros, ainda que se realizassem permeadas por dificuldades.
} 
na necessidade de traçar uma análise para desvelar o "sentido" adquirido pela flexibilidade, a saber: a conformação de um tipo de trabalho/trabalhador nos moldes exigidos pelo atual estágio de acumulação capitalista.

Assim, nos discursos do governo e dos setores do capital, uma das saídas para enfrentar a crise expressa nas elevadas taxas de desemprego estabelecidas e nas quedas de produtividade, consiste justamente na recorrência à flexibilidade como um mecanismo primordial. Diante desse quadro, a proposição e execução das famigeradas "reformas trabalhistas"2 ganham destaque ${ }^{3}$. Assim, tais reformas têm sido pautadas por inúmeros governos, sob a alegação de promoverem uma "modernização" ou "adequação" da estruturação jurídica do trabalho com as exigências dos tempos atuais.

Na particularidade brasileira, como expõe Trindade (2019; 2020), são emblemáticos dos ataques orquestrados contra o parco nível de trabalho protegido/regulamentado existente entre nós, a formulação e aprovação da lei que prevê a liberalização total da terceirização, inclusive para as atividades fins (lei 13.429/2017) e aquilo que seria a "pedra de toque" do governo ilegítimo de Michel Temer, a saber: a Reforma Trabalhista (lei oํ 13.467/2017). Essa reforma ganha forte impulso após o golpe sucedido em 2016 e se consolida em 2017, com a aprovação do texto pelo senado, animando vivamente a burguesia que, já há muito tempo indicava, por meio de suas entidades representativas, um conjunto de medidas e proposições a serem observadas, como se vê, por exemplo, com as 101 propostas apresentadas pelo Conselho Nacional da Indústria (CNI).

Desde os primeiros debates instaurados sobre essa temática, um argumento recorrentemente utilizado pelos setores dominantes para destacar a relevância da reforma trabalhista enfatizava a necessidade da reformulação da Consolidação das Leis do Trabalho (CLT) para sintonizá-la com a realidade contemporânea, ou, como sugere o relator do projeto, já no início de seu texto, para acompanhar o "espírito desse tempo" (PARECER DA REFORMA, 2017).

De imediato, esse argumento expressa uma fragilidade inconteste, pois, desde de sua criação, em 1943, a CLT passou por sucessivas e vultuosas alterações, a partir das próprias disputas estabelecidas entre os representantes do capital e do trabalho. Nesse sentido, a substancialidade das modificações operadas com a promulgação da Lei ํำ13.467/2017, não corrobora os argumentos daqueles que enfatizavam o caráter "arcaico", "velho" e "ultrapassado" da legislação trabalhista anterior, tornando cristalina a opção de classe que motiva tal reforma: trata-se de flexibilizar ainda mais a contratação e utilização da força de trabalho para atender aos interesses dos setores dominantes da sociedade brasileira.

Os arautos da reforma prometiam que as alterações na legislação trabalhista, em mais de uma centena de pontos propostos, propiciariam melhorias no âmbito do mercado de trabalho brasileiro, sobretudo com a regularização de empregos e com a criação de novos postos de trabalho - o

\footnotetext{
${ }^{2}$ Neste trabalho, quando utilizarmos a expressão "reforma trabalhista" estaremos aludindo ao que, em verdade, representa uma contrarreforma, como qualificou Elaine Behring (2003). Esta autora lembra que, historicamente, o termo "reforma" esteve associado a uma perspectiva progressista, relacionada a um conjunto de defesas pensadas por setores dos movimentos de trabalhadores e, em especial, da social-democracia, com vistas à melhoria das condições de vida dos sujeitos, tal como se sucedeu com a instalação do Welfare State, nos chamados 30 anos gloriosos. Nos dias que correm, há uma utilização político-ideológica do termo por parte dos setores dominantes que reivindicam a necessidade de realizar reformas que, ao fim e ao cabo, expressam a desestruturação de direitos.

${ }^{3}$ Inúmeros sociólogos do trabalho produziram alertas sobre os efeitos que tais medidas poderiam acarretar para a classe trabalhadora. Partidos políticos, movimentos sociais e setores organizados da sociedade saíram as ruas na tentativa de quebrar a onda de retrocessos que vem se avolumando cada vez mais.
} 
que não ocorria, até então, porque, para os empregadores/empresários, contratar os trabalhadores representava uma ação excessivamente onerosa, custosa.

Todavia, as promessas alardeadas não se concretizaram. Decorridos mais de dois anos desde a aprovação das leis, já nos é possível atestar o contrário daquele discurso propalado pelo ministro da Fazenda, Henrique Meirelles, segundo o qual a reforma trabalhista deveria gerar seis novos milhões de emprego no Brasil (MARTELLO, 2017).

Em interessante estudo, após analisar diversas hipóteses e variáveis, Filgueiras (2019) demonstra que não há uma relação de causalidade entre o desenvolvimento da reforma trabalhista e a materialização de trabalhos novos e formalizados. Em verdade, "O desemprego total em outubro de 2017 contemplava 26,554 milhões de pessoas (23,8\%), contra 28,524 milhões em maio (25\%), recorde da série histórica da PNAD" (FILGUEIRAS, 2019, p. 35).

Assim, após a implementação da reforma trabalhista, nenhuma alteração de maior vulto pôde ser identificada no que tange a melhorias nas condições de trabalho dos brasileiros. Ao revés, para os empresários, há muito o que comemorar. Ora, concretizada a reforma, “[...] a economia de recursos pelos empregadores [sobretudo com as normas que restringem o acesso do trabalhador à justiça e com o estabelecimento de desligamentos por acordos entre as partes] pode já ter sido colossal, e ela tende a crescer" (FILGUEIRAS, 2019, p. 32).

Com a reforma trabalhista, um conjunto de aspectos emergem, dando continuidade ao processo de desestruturação do mercado de trabalho no Brasil, quer agravando as péssimas condições de trabalho já estabelecidas, quer produzindo novas tendências à precarização do trabalho. Nessa direção, corroboramos com a análise de Krein e Olivera (2019), para os quais a reforma trabalhista atuou em dois sentidos articulados: de um lado, concedeu estatuto legal a um conjunto de práticas e formas de inserção do trabalho flexíveis para que não houvesse margem de questionamento da justiça do trabalho, e de outro, ampliou as possibilidades de exploração por parte do empresariado, no que tange à contratação, uso e remuneração do trabalho.

Nessa direção, para discorrermos mais detalhadamente sobre a situação do mercado de trabalho no Brasil ante as novas possibilidades de contratação da força de trabalho propiciadas pela contrarreforma, estruturamos este artigo a partir de três itens principais. Eles apresentam, respectivamente, um panorama do significado do trabalho intermitente, terceirizado (para atividades fins) e "autônomo", oferecendo, ao mesmo instante, elementos críticos para pensarmos os limites e as dificuldades que permeiam essas modalidades contratuais em nossas latitudes.

Finalizamos o artigo tecendo uma reflexão sobre o sentido geral adquirido pela atual contrarreforma, qual seja: há uma mudança histórica no nível de precarização do trabalho no Brasil e, como corolário, na degradação da classe trabalhadora, submetida cada vez mais a situações de pauperização absoluta. Esperamos que o texto possa suscitar novas reflexões e inquietações nos leitores, contribuindo para adensar os debates nesse campo temático.

\section{Trabalho Intermitente: a conformação do trabalhador just-in-time}

Em nossa realidade, a mais ilustrativa forma de flexibilização da jornada de trabalho se cristaliza a partir da expansão do trabalho intermitente. No texto que dá concretude a reforma trabalhista no Brasil, podemos ler a seguinte passagem a respeito desta modalidade de contratação:

$\S 3^{\circ}$ Considera-se como intermitente o contrato de trabalho no qual a prestação de serviços, com subordinação, não é contínua, ocorrendo com alternância de 
períodos de prestação de serviços e de inatividade, determinados em horas, dias ou meses, independentemente do tipo de atividade do empregado e do empregador, inclusive as disciplinadas por legislação específica (BRASIL, 2017).

A legislação indica, ainda, que a convocação dos trabalhadores intermitentes pode ocorrer mediante qualquer meio de comunicação, com no mínimo três dias de antecedência, momento no qual deverá ser indicada a quantidade de horas disponíveis para que o trabalhador estabeleça suas atividades. Após a solicitação por parte do empregador, o trabalhador tem o prazo de um dia para se posicionar com a aceitação ou não da oferta (BRASIL, 2017).

Nesse sentido, com o trabalho intermitente não é possível prever a quantidade de horas que serão dispendidas no trabalho, já que os chamados não possuem nenhuma regularidade determinada. Isso tem uma implicação direta na composição dos rendimentos financeiros dos trabalhadores. Dessa forma, necessitarão se adequar a um salário volante e volátil, sem saber quanto possuirão em cada mês, correndo o risco, inclusive, de não conseguirem arcar com as suas despesas de primeira necessidade. De fato, "[...] o contrato intermitente coloca o trabalhador em uma condição de alta instabilidade, incerteza e insegurança sobre sua própria reprodução social" (KREIN; ABILIO, et. al, 2018, p. 108).

Para os setores capitalistas, o propósito do chamado trabalho intermitente reside justamente na vantagem (acentuada flexibilidade) em utilizar o trabalhador apenas em momentos precisos ou, como sugeriu Ludmila Abilio (2017), no modo just-in-time. Se nos marcos do sistema de produção toyotista, se priorizava a confecção das mercadorias a partir da utilização dos lapsos temporais estritamente necessários a tal finalidade (PINTO, 2010), em meio à disseminação do trabalho intermitente a presença dos trabalhadores, nas indústrias e nos serviços, em geral, também deve ocorrer em tempos muito delimitados e precisos.

O trabalhador just-in-time é aquele que produz no tempo certo, na quantidade e produtividade adequada, utilizando apenas a fração de tempo necessária para desempenhar as atividades. A utilização da força de trabalho se dá mediante uma precisão, sem deixar espaço para ócio ou para o manejo "inadequado" do tempo. A exatidão do tempo de trabalho se contrasta fortemente com a inexatidão das possibilidades de sobrevivência dos trabalhadores que, regidos por essa forma de contrato, vivem em uma verdadeira corda bamba, da qual podem despencar a todo instante.

Na realidade brasileira, a disputa pelo tempo de trabalho se mostra deveras importante. Assim, a observância dos itens da nova legislação trabalhista nos mostra, em um sentido geral, a tonalidade das investidas na direção de materializar uma jornada de trabalho cada vez mais flexível para os trabalhadores, nos moldes já disseminados pelos princípios e direcionamentos norteadores da reestruturação produtiva.

Diante de condições tão adversas, é correto afirmar que o trabalho intermitente fragiliza o trabalhador, do ponto de vista objetivo e subjetivo, contribuindo diretamente para exponenciar o processo de precarização, flexibilização e degradação do trabalho. Em se tratando do caso brasileiro, o relator do projeto que regulariza esta modalidade de contratação, se esforça para fazer transparecer a ideia de que o trabalho intermitente (e seu caráter descontínuo) estaria mais direcionado para determinados setores do mercado. Diz ele: “[...] o trabalho prestado nessa modalidade contratual poderá ser descontínuo para que possa atender a demandas específicas de determinados setores, a exemplo dos setores de bares e restaurantes ou de turismo". (RELATÓRIO DA REFORMA, 2017, p. 50 - grifos nossos). 
Por certo, o critério para a escolha desse tipo de trabalho não se sustenta apenas na funcionalidade que, por ventura, apresente em determinados setores. Antes, expressa uma opção deliberada do contratante, por vislumbrar, com ela, maior possibilidade de exploração da força de trabalho e, consequentemente, mais vantagens financeiras em sua utilização.

Assim sendo, o trabalho intermitente pode e deve se expandir pelos mais diversos espaços da sociedade. Nesse sentido, é fundamental atentar para a situação de precarização do trabalho feminino, dado que, por um lado, os campos empregatícios que mais têm recrutado trabalhadores via contrato intermitente - com destaque para o setor de serviços - são ocupados, majoritariamente, por pessoas do sexo feminino e, por outro, as mulheres ainda são as mais acometidas pelo desemprego no Brasil, tal como aponta Marilane Teixeira (2017).

Dessa feita, é possível projetar a existência de número cada vez maior de trabalhadores submetidos a essa modalidade de trabalho, como já vem ocorrendo em outros países do globo. Ao analisar a experiência do zero-hour contract britânico, a pesquisa de Maeda (2019) revelou, dentre outros casos, a situação de um grande varejista que "[...] mantinha 90\% de seus 23 mil funcionários contratados sob esta modalidade" (2019, p. 125) ou seja, há a possibilidade de essa forma de contratação se generalizar, mesmo nos casos em que as atividades exercidas pelos trabalhadores possuam caráter contínuo.

Na particularidade brasileira, a aceitação das ofertas de trabalho, em quaisquer condições, também é favorecida pelo elevado nível de desemprego e pelas dificuldades de inserção dos trabalhadores no mercado formal de trabalho, sendo essa uma marca histórica de nosso país, como demonstra Barbosa (2008). Nessas condições, os trabalhadores tendem a suprimir sua margem de "escolha" e passam a aceitar, quase indeterminadamente, todos os trabalhos oferecidos por receio de que as ofertas diminuam ou cessem em virtude da recusa, desconstruindo a ideia de uma suposta "liberdade" dos trabalhadores para aceitarem ou não os chamados, tal como também foi constatado na experiência britânica. (MAEDA, 2019).

$\mathrm{Na}$ medida em que o trabalho intermitente avança, expande-se, na mesma proporção, o número de trabalhadores em formas de subemprego, favorecendo o escamoteamento da real situação de instabilidade e precarização desses sujeitos, pois, em um curto espaço de tempo, o trabalhador pode transitar, repetidas vezes, de uma situação de desemprego para uma condição de emprego, a depender de como se registram suas relações de trabalho.

Dando continuidade à nossa análise, poderíamos destacar que, na experiência britânica, ainda de acordo com os estudos de Maeda (2019), o trabalho flexível é apresentado para a sociedade como uma alternativa para inserção de jovens e de desempregados no âmbito do trabalho. Em se tratando da realidade brasileira, também nos deparamos com a construção de um discurso semelhante. Podemos comprovar tal assertiva ao observar a indicação feita pelo relator do projeto. Vejamos o que expõe:

[...] há que se considerar o efeito social da implantação do contrato intermitente em situações como a obtenção do primeiro emprego, especialmente para os estudantes, que poderão adequar as respectivas jornadas de trabalho e de estudo da forma que lhes for mais favorável (PARECER DA REFORMA, 2017, p. 50)

O referido relator frisa o trabalho intermitente como uma saída para que os jovens estudantes alcancem os seus primeiros empregos, inclusive destacando a importância desse tipo de vínculo para que consigam conciliar as duas atividades (trabalho e estudo). Contudo, dado o contexto de avanço das novas modalidades de contratação, em que, amparado pelas leis, o trabalho "atípico" 
se camufla em trabalho "típico", a nova geração de proletários e os jovens trabalhadores atuais não terão o trabalho intermitente apenas como uma forma para entrada no "primeiro emprego", mas sim, como o modo corrente de inserção no universo laboral.

Nessa direção, Filgueiras, Bispo e Coutinho (2018) constroem um interessante argumento para demonstrar que, sob a égide do trabalho intermitente, o processo de subsunção do trabalho ao capital é expressivamente ampliado. Os autores indicam que, em uma típica condição de labor, os trabalhadores se tornam apêndices da acumulação durante determinada jornada laboral. Todavia, algo diferente ocorre com o trabalho intermitente, posto que, nessa situação, os trabalhadores se encontram, permanentemente, à disposição dos empregadores, à espera de uma chamada, de anúncio ou de uma proposta de trabalho. Em síntese - e para usar as suas palavras:"[...] da subsunção do trabalho ao capital durante a jornada, passa-se à subsunção da totalidade da vida do trabalhador ao capital. A vida do indivíduo tende a ser um apêndice da dinâmica do capital, uma eterna espera por um chamado para trabalhar" (FILGUEIRAS; BISPO; COUTINHO, 2018, p. 130).

Ademais, cumpre frisar que a legislação brasileira se reveste de um caráter punitivista para o trabalhador, na exata medida em que prescreve determinadas penalidades para o caso de descumprimento do acordo firmado, como se pode observar a partir da apreensão do artigo 452-A, especificamente em seu $\S 4^{\circ}$, quando estabelece:

Aceita a oferta para o comparecimento ao trabalho, a parte que descumprir, sem justo motivo, pagará à outra parte, no prazo de trinta dias, multa de 50\% (cinquenta por cento) da remuneração que seria devida, permitida a compensação em igual prazo (BRASIL, 2017 - grifos nossos).

Ora, diante de uma relação tão instável e insegura a qual estão submetidos os trabalhadores com esse tipo de contrato, não parece razoável uma medida como essa, pois, na prática, pode se constituir fator para a negação de ofertas de trabalho melhor remuneradas surgidas após a aceitação de determinadas convocações ou, ainda, como sugeriu Maeda (2019), levar os trabalhadores a exercerem suas atividades em condições adversas, por exemplo, acometidos por problemas de saúde. A lógica é muito clara e se reforça a cada ponto apresentado pela nova legislação: ao empregado, toda a flexibilidade possível na utilização da força de trabalho. Ao trabalhador, toda a sorte de incertezas e paupéria.

Nesse contexto, também se torna evidente a dificuldade de organização coletiva dos trabalhadores regidos por essa modalidade contratual, por diversos fatores.

Um deles diz respeito a inexistência de uma relação orgânica dos trabalhadores intermitentes com os postos de trabalho ocupados, ou seja, as atividades por eles executadas são marcadas pela eventualidade, dificultando a constituição de relações políticas com os demais trabalhadores, tanto os regidos por contratos formais/típicos, quanto com os demais intermitentes. Inclusive, o caráter da eventualidade é reforçado pela legislação em apreço, ao expor: "O período de inatividade não será considerado tempo à disposição do empregador, podendo o trabalhador prestar serviços a outros contratantes" (BRASIL, 2017).

Outro fator relevante para pensar as dificuldades de organização política dos trabalhadores intermitentes se relaciona, especialmente, em sua relação com o movimento sindical. 0 pagamento das taxas e contribuições se constituem como fatores limitadores da inserção dos trabalhadores intermitentes nesse espaço de organização coletiva, dado que seus salários são incertos e a remuneração, em geral, é reduzida, tendo por comparação os sujeitos contratados de forma típica. 


\section{Terceirização das atividades fins: "a precarização como regra"}

Como sabemos, do ponto de vista geral, a terceirização galga um papel de destaque a partir das reestruturações produtivas que operam a "transição" do modo de organização e gestão fordista/taylorista para o toyotista. No âmbito do sistema fordista, a maioria da produção era realizada no interior da fábrica, obedecendo a lógica da horizontalização. Por sua vez, o toyotismo apregoa a necessidade de uma externalização de parcela da produção (Cf. GOUNET, 1999). Para a empresa "liofilizada" ou "enxuta" funcionar corretamente, uma parte da produção passa a ser realizada em outros espaços. Trata-se mesmo de uma transferência de atividades para outras empresas: eis os fundamentos da terceirização. Como enfatiza Ricardo Antunes, "Enquanto na fábrica fordista aproximadamente $75 \%$ da produção era realizada no seu interior, a fábrica toyotista é responsável por somente $25 \%$ da produção, tendência que vem se intensificando ainda mais" (ANTUNES, 2009, p. 56).

O destaque para a transferência de atividades é importante. Tratava-se, nesse momento, de incumbir determinada empresa para a realização de um serviço importante para a indústria, de modo que essa (terceirizada) não interferisse na atividade finalística daquela. No entanto, com a lei n 13.429/2017 aprovada no Brasil, temos uma expressiva mudança na forma como a terceirização passou a ser conduzida, porque, com ela, “[...] iniciou-se um processo de contratação de mão de obra por meio de terceiros para laborar nas atividades essenciais da empresa tomadora de serviços" (FONSECA, 2018, p. 96).

Ou seja, até 2017 a terceirização se estabelecia a partir da transferência das chamadas atividades-meio, situação que muda radicalmente com a possibilidade de terceirizar, além das atividades-meio, também as atividades-fim, tal como prevê a nova legislação, o que é extremamente nefasto. Qual a lógica em terceirizar uma atividade/função indispensável para a fabricação de determinado produto? A resposta só pode ser uma: a terceirização da atividade-fim ocorre retirando e/ou reduzindo os direitos dos trabalhadores ou, para sermos mais precisos, a terceirização das atividades-fim expressa uma burla que precariza as condições e relações de trabalho.

Historicamente, a terceirização do trabalho se fez presente na estruturação do mercado de trabalho brasileiro e, como corolário, plasmou impactos regressivos para os trabalhadores. De toda forma, mesmo que esse seja um fenômeno constante entre nós, Antunes e Druck (2015) apontam a existência de uma epidemia do trabalho terceirizado nos anos 2000, em alusão à forte presença dessa modalidade de contratação. Nesse marco temporal, o Tribunal Superior do Trabalho (TST) produziu a súmula 331, objetivando, basicamente, estabelecer parâmetros plausíveis para a contratação de trabalhadores sob essa forma.

Contudo, com a aprovação da lei nº 13.429/2017, tal súmula perde validade e, dessa forma, o único recurso que os agentes fiscalizadores (em especial o Ministério Público do Trabalho) possuíam para frear as arbitrariedades do trabalho terceirizado foi solapado. Com a possibilidade de terceirizar também as atividades-fim, o capital pôde operar uma flexibilização incontrolável da força de trabalho, acarretando consequências sociais desastrosas.

É nesse contexto que Graça Druck (2017), importante estudiosa da temática no Brasil, afirma que a materialização da atual legislação contribui para endossar o significado da terceirização na sociedade brasileira, qual seja, "a precarização como regra". A autora indica, apoiada em um conjunto amplo de pesquisas e investigações realizadas nos últimos 25 anos no Brasil, no âmbito dos mais variados setores, a incontestável relação entre precarização do trabalho e terceirização (DRUCK, 2017), a qual se aprofunda no tempo recente. 
Evidentemente, existe hoje uma dificuldade de contabilizar a quantidade de trabalhadores terceirizados. A pesquisa levada a cabo pelo Departamento Intersindical de Estatística e Estudos Socioeconômicos (DIEESE), em parceria com a Central Única dos Trabalhadores (CUT), estimou o número em cerca de 12,5 milhões no ano de 2014 (DIEESE, 2017). Nos dias que correm, a dificuldade de mensurar o quantitativo de trabalhadores terceirizados persiste, ainda que, tendo em conta a construção de parâmetros de avaliação desse fenômeno, seja possível identificar, desde a aprovação da lei n⿳o 13.429/2017 e da Reforma Trabalhista, uma “[...] clara indicação de que a terceirização continua avançando fortemente após a Reforma, sendo a modalidade de contratação flexível mais expressiva". (KEIN; OLIVEIRA, 2019, p. 108).

Os alertas sobre os malefícios da terceirização para os trabalhadores são constantes e derivam de diversas instituições e pesquisadores. Como revela a procuradora do trabalho do MPT, Vanessa Fonseca (2018), são comuns as denúncias de trabalhadores terceirizados laborando sem o gozo de férias, sem descansos, sem condições dignas de habitação, alimentação e, no pior dos casos, exercendo suas atividades em condições análogas à escravidão. Sobre esse último tema, Giovanni Alves (2017, p. 339) nos apresenta um dado digno de nota: “[...] 90\% dos 40 maiores resgates em todo o Brasil nos últimos 4 anos tinham trabalhadores terceirizados".

No âmbito global, a expansão da terceirização é fortemente acompanhada pela concorrência entre as distintas empresas que, para sobreviverem, necessitam atender às exigências das indústrias compradoras. No estudo desenvolvido pelos chineses Chan, Pun e Selden (2019) defrontamo-nos com uma análise acerca da situação dos trabalhadores terceirizados da Foxconn, empresa que fornece produtos eletrônicos para a Apple. Os relatos presentes no texto, fazem inferência à pressão que a Apple consegue exercer na empresa terceirizada, no que tange a aspectos como: aumento da produção em curto espaço de tempo, modificação no design das mercadorias e barateamento dos produtos oferecidos, sobretudo nos contextos de maior recessão econômica.

Como ressaltam os autores acima referidos, “[...] as mudanças indicam a crescente capacidade da Apple de pressionar a Foxconn a aceitar margens mais baixas, enquanto esta se acomoda às demandas da Apple em relação a mudanças técnicas e grandes pedidos" (CHAN; PUN; SELDEN, 2019, p. 33). Diante desse contexto, questionamos: como a Foxconn consegue atender as demandas - às vezes repentinas, mas sempre complexas - da Apple? A resposta, certamente, passa por nossa compreensão dos mecanismos de extensão da jornada de trabalho, de intensificação das operações realizadas pelos trabalhadores e do rebaixamento do valor da força de trabalho.

Com a terceirização, fomenta-se uma espécie de leilão invertido do valor da força de trabalho. Nas negociações entre as empresas terceirizadas e as empresas-sede, vence aquela terceirizada que mais conseguir explorar e precarizar a força de trabalho, plasmando uma expressiva degradação do ser social que trabalha. No caso chinês, ainda de acordo com a pesquisa de Chan, Pun e Selden (2019), a ocorrência de suicídios de jovens trabalhadores das empresas terceirizadas aponta a gravidade das condições e relações de trabalho estabelecidas.

Recuperar esse estudo é significativo para termos dimensão dos malefícios provocados por essa forma de inserção laboral, e essa lógica, com particularidades diversas, também se materializa no Brasil.

Entre nós, os estudos desenvolvidos têm demonstrado que os salários dos trabalhadores terceirizados são inferiores em comparação com o dos trabalhadores “estáveis". A redução pode alcançar cerca de 27,1\% (ALVES, 2017), mesmo quando ocupando as mesmas funções e realizando iguais atividades no âmbito da mesma empresa. Nesse contexto, Alves segue indicando que: 
As empresas terceirizadas abrigam as populações mais vulneráveis do mercado de trabalho: mulheres, negros, jovens, migrantes e imigrantes. Esse "abrigo" não tem caráter social, mas é justamente porque esses trabalhadores se encontram em situação mais desfavorável, e por falta de opção, submetem-se a esse emprego (ALVES, 2017, p.339).

Diante do exposto, podemos afirmar que a terceirização atinge frações e segmentos sociais da classe trabalhadora historicamente submetidos a condições de precarização do trabalho, e, certamente, com o avanço dessa forma de contratação, eles serão os mais impactados pelos efeitos desse processo, aprofundando as disparidades sociais, econômicas, culturais e políticas vivenciadas.

Nesse diapasão, o reduzido salário se associa a outro fenômeno, a saber: as atividades realizadas por trabalhadores terceirizados contemplam o maior número de acidentes de trabalho. Cumpre destacar que diversos estudiosos (Cf. dentre outros, NAVARRO; LOURENÇO, 2017) e organismos já demonstraram que os trabalhadores terceirizados são mais acometidos por agravos em sua saúde, em decorrência do tipo do vínculo firmado e das condições e relações de trabalho estabelecidas. Apenas a título de exemplo, poderíamos mencionar a nota técnica do Departamento Intersindical de Estatística e Estudos Socioeconômicos (DIEESE) que demonstra que os casos de afastamento por acidentes de trabalho dos trabalhadores terceirizados são muito superiores se comparados com o quantitativo dos demais trabalhadores (com contratos "estáveis") afastados do trabalho pelo mesmo motivo. (DIEESE, 2017).

Esse dado pode ser aprofundado pelos estudos de Antunes e Praun (2015), os quais observam traços da nova morfologia da classe trabalhadora no Brasil, nos diversos setores e campos, enfatizando que as condições dos trabalhadores terceirizados são fortemente marcadas pela desresponsabilização das empresas diante do agravamento das condições de saúde desses sujeitos.

Além disso, cabe frisar outro importante aspecto: os trabalhadores terceirizados estão submetidos a um tempo de permanência reduzido nas empresas que ocupam. Em verdade, a quantidade de desligamentos em vínculos de trabalho tipicamente terceirizados é bastante elevada no Brasil, e isso nos fornece pistas interessantes para pensarmos em um conjunto de indicadores sociais, mas também nos permite avançar na compreensão do papel exercido pela terceirização na materialização do elevado grau de rotatividade da força de trabalho no Brasil.

De acordo com o estudo realizado por pesquisadores do DIEESE (PELATIERI et al, 2018) compreendendo o lapso temporal de 2007-2014, o tempo médio de permanência de um trabalhador em atividades tipicamente terceirizadas em seu espaço de trabalho era de aproximadamente dois anos e dez meses, ao passo em que os trabalhadores inseridos em atividades tipicamente contratantes computavam um tempo médio de cinco anos e dez meses, ou seja, um período duas vezes maior em comparação com o das atividades terceirizadas.

Com a aprovação da lei nº 13.429/2017, parte da reforma trabalhista em curso no Brasil, e dada a importância que o trabalho terceirizado tem assumido, a tendência é que esse quadro se complexifique e que a rotatividade da força de trabalho experimente oscilações mais contantes, afetando diretamente a classe trabalhadora, até mesmo porque as demissões já recorrentes nos marcos da legislação anterior, agora, passam a ser ainda mais facilitadas com as alterações jurídicas que condicionam o desligamento dos trabalhadores a partir de "acordos" entre as partes.

Cumpre ressaltar, ainda, como indica Fonseca (2018), que a terceirização implica uma redução de custos para o empresário, pois a contratação de alguns profissionais (técnico de segurança, médico do trabalho, etc.) se faz obrigatória somente quando as empresas possuem 
um quadro de trabalhadores permanentes em certo quantitativo. Ocorre, efetivamente, que as indústrias operam com uma quantidade determinada de trabalhadores suficiente para realizar suas atividades, mas, sendo grande parte deles terceirizada, eximem-se de cumprir essa normativa legal. Em suas palavras:

Dessa forma, embora no ambiente laboral permaneça a mesma quantidade de trabalhadores, aqueles contratados por terceiros não compõem a base de cálculo da Cipa e do SESMT [Serviço Especializado em Engenharia de Segurança e em Medicina do Trabalho], prejudicando a fiscalização do cumprimento de normas de segurança e saúde no trabalho e favorecendo o aumento dos índices de acidentes. (FONSECA, 2018, p. 99).

Os dados e indicadores apresentados nas linhas acima são interessantes porque nos permitem visualizar e nos levam a refletir sobre um contexto de incertezas, inseguranças e, sobretudo, de degradação dos trabalhadores inseridos no trabalho terceirizado. De fato, como discorre Alves (2017), essa modalidade laboral não pode se alastrar sem provocar, junto consigo, um conjunto de danos existenciais para o ser que trabalha.

\section{Trabalho autônomo: entre a "coerção" e a "necessidade"}

Assim como a terceirização, o chamado trabalho autônomo também se desenvolve no Brasil de maneira corrente e acentuada. No tempo recente, tem ganhado destaque a transferência de contratos de trabalhadores assalariados para Pessoas Jurídicas (PJ). Por certo, não se trata apenas de uma mudança de nomenclatura. O que está em tela é a possibilidade de tratar o trabalhador desconsiderando um conjunto de direitos que deveriam ser estabelecidos a partir de uma relação contratual como pessoa física ${ }^{4}$. Ou, em outras palavras, trata-se de uma descaracterização do vínculo de emprego, com vistas a exponenciar a flexibilização do trabalho.

Essa descaracterização ocorre na medida em que as alterações propostas contribuem para obnubilar, ou mesmo desconstruir, os elementos que a CLT apontava como fundamentais na constituição de uma relação empregatícia, a saber: alteridade, onerosidade, pessoalidade, não eventualidade e subordinação jurídica (MARTINS, 2003).

Ora, se o vínculo estabelecido não pode, à luz da legislação existente, ser considerado como emprego, de imediato temos que a atuação dos órgãos fiscalizadores de irregularidades na contratação da força de trabalho se vê comprometida. Não custa lembrar que, até julho de 2019, as Varas do Trabalho contabilizaram o total de 67.343 processos vinculados ao reconhecimento de relação de emprego, sendo esse um temas mais recorrentes nesse âmbito (TST, 2019). Se a demanda é, em alguma medida, expressiva, isso demonstra que os casos de burla das relações trabalhistas são uma realidade concreta e, certamente, agravar-se-ão com os delineamentos assumidos pela recente contrarreforma em curso no Brasil.

Em nosso país, a inserção dos trabalhadores nessa modalidade de contratação, nos mais diversos setores e áreas, incia-se já na primeira metade dos anos 2000, momento no qual se promulgou a lei $n^{\circ} \mathbf{1 1} .196 / 2005$, responsável por regulamentar a contratação de trabalhadores intelectuais sob essa modalidade laboral, como se pode aferir a partir da leitura abaixo:

\footnotetext{
${ }^{4}$ Associado a isso, tem-se a obrigação com o cumprimento dos encargos tributários que daí decorrem, anunciando uma situação extremamente desfavorável para os trabalhadores, semelhante ao que vivenciaram os trabalhadores portugueses com o trabalho por Recibos Verdes (Cf. SOEIRO, 2015).
} 
Art. 129. Para fins fiscais e previdenciários, a prestação de serviços intelectuais, inclusive os de natureza científica, artística ou cultural, em caráter personalíssimo ou não, com ou sem a designação de quaisquer obrigações a sócios ou empregados da sociedade prestadora de serviços, quando por esta realizada, se sujeita tão-somente à legislação aplicável às pessoas jurídicas, sem prejuízo da observância do disposto no art. 50 da Lei no 10.406, de 10 de janeiro de 2002 - Código Civil. (BRASIL, 2005)

Todavia, desde que veio à tona, era possível constatar um número cada vez mais amplo de trabalhadores vinculados a essa modalidade de trabalho, mesmo exercendo atividades e funções que não poderiam ser caracterizadas como "trabalho intelectual". Atualmente, tal realidade continua presente e vem se ampliando, sobretudo no âmbito do setor de serviços - e isso ocorre, quase sempre, em meio ao escamoteamento das relações laborais estabelecidas nesse espaço. Como ressalta Amanda Silva: “[...] o que se tem verificado é a contratação de diversos trabalhadores que prestam serviços de natureza 'não intelectual' camuflados de trabalhadores intelectuais, com o intuito de fraudar a aplicação da legislação trabalhista" (SILVA, 2018, p. 103).

Nessa esteira, a disseminação das formas de trabalho autônomo ocorre, muitas vezes, encoberta pelo manto ideológico do empreendedorismo. A esse respeito, é ilustrativo o estudo desenvolvido pela Global Entrepreneurship Monitor (GEM), no ano de 2016, por meio do qual se constatou a existência de 48 milhões de empresários no Brasil (GEM, 2016). Esse número, ainda de acordo com a mesma fonte, saltou para 52 milhões no ano de 2018 (GEM, 2018), fato anunciado com alegria por algumas instituições, estampando a notícia: “Brasil teve $2^{\circ}$ melhor desempenho em empreendedorismo em 2018"(AGÊNCIA BRASIL, 2019).

Em um primeiro momento, o expressivo número de empresários/empreendedores pode nos causar algum tipo de espanto, principalmente se o confrontamos com o quantitativo de trabalhadores inseridos formalmente no mercado de trabalho brasileiro. Contudo, ao avançar na leitura dessas pesquisas, e na observação atenta de outros aspectos por elas apontados (GEM 2016; 2018), deparamo-nos com um dado importante para entender quem são esses "empresários": Em 2016, 50,2\% deles faturavam até 1 mil reais por mês, ou seja, um pouco mais do valor estipulado para o salário mínimo no Brasil. Em 2018, 35,7\% possuíam renda variando entre 1 e 2 salários mínimos.

Outro dado interessante diz respeito ao número de empregados que esses empreendedores contratam. A pesquisa aqui em apreço (GEM, 2018) indica que cerca de $80 \%$ desses novos empresários não contratam nenhum funcionário. Assim, ao que nos parece, a condição de empresário revela apenas a transfiguração da situação de desempregado para a de "empreendedor", trabalhador autônomo ou qualquer que seja a nomenclatura utilizada para classificar esse feito.

Estudiosos da área (Cf. dentre outros, FILGUEIRAS, 2019; TAVARES, 2004, 2018), tecem análises críticas que nos permitem entender o lugar do empreendedorismo e do trabalho dito autônomo na atual fase de acumulação capitalista. A partir desses aportes, podemos depreender que, em alguns casos, a assunção do posto de PJ, por parte do empregado, ocorre mediante imposição do empregador, estabelecendo-o como um requisito indispensável para efetuar a contratação. Nessa situação, o trabalhador se transforma em PJ para fugir do desemprego, por coerção. Em outros casos, contudo, os trabalhadores desempregados aderem ao trabalho autônomo como alternativa ao desemprego, ou melhor, do "empreendedorismo por necessidade".

Trata-se, em síntese, da continuidade das formas de inserção subordinada e precarizada no mercado de trabalho brasileiro. Por isso mesmo, como sugeriu Gregório Duvivier, em uma 
crítica ácida à expansão desse fenômeno no Brasil, ao invés de "Empresariado" esse segmento populacional deveria ser denominado como "Emprecariado".

Nesse percurso, podemos dizer que o ano de 2008 marca um momento importante para refletirmos sobre a situação dos trabalhadores autônomos no Brasil, uma vez que é desse período a instauração da lei que cria a figura do Microempreendedor Individual (MEI) ${ }^{5}$. Basicamente, o MEI diz respeito a um profissional autônomo (entendido como empreendedor) que se registra em uma plataforma disponibilizada pelo governo federal a fim de obter o Cadastro Nacional da Pessoa Jurídica (CNPJ), documento que lhe confere algumas possibilidades no campo do trabalho.

Desde o surgimento da lei, o número de MEIs vem se elevando exponencialmente. Em 2019, decorridos 10 anos desde a sua criação, superou o quantitativo de 8 milhões de pessoas cadastradas, conforme aponta o portal do empreendedor (PORTAL DO EMPREENDEDOR, 2019).

Recentemente, Darlan Alvarenga (2019) produziu interessante matéria, publicizada no Portal G1, na qual discorria sobre a expansão dos MEIs no Brasil, momento em que recuperou o relato de dois trabalhadores inscritos nessa modalidade de trabalho para ilustrar o perfil desse tipo de Microempreendedor Individual.

Um deles se refere ao bikeboy Rafael Cruz. O jovem paulistano de 21 anos de idade relata ter efetuado o seu cadastro como MEI para trabalhar entregando alimentos para empresas como iFood e Uber Eats, que figuram entre as mais acionadas para esse tipo de atividade. E o fez após a dispensa de seu emprego anterior (em uma rede de lanchonetes). Em seu relato, Rafael indica, ainda, que obtém uma renda diária de cerca de $\mathrm{R} \$ 80$, nos dias mais favoráveis, ou seja, quando consegue entregar um maior número de encomendas.

O outro caso apresentado por Alvarenga (2019) é o de Gabriel Lima, trabalhador autônomo inscrito em condições laborais semelhantes às de Rafael. Na matéria, embora Gabriel ressalte os benefícios de sua condição de microempreendedor, em especial no tocante à possível definição dos dias em que deseja trabalhar, salta aos olhos o grau de precarização a que está submetido. Senão, vejamos o que indica a reportagem:

O entregador sequer tem bicicleta própria. Ele usa as "magrelas" das estações de aluguel de bicicletas espalhadas pela cidade e diz que sua meta é conseguir juntar dinheiro para dar entrada na compra de uma moto, e assim poder aumentar o volume de entregas. (ALVARENGA, 2019, s/p).

Deparamo-nos, todos os dias, nas grandes e médias cidades brasileiras, com jovens como Rafael e Gabriel. Eles cruzam nossos caminhos em suas bicicletas, quase sempre amontoados por mochilas de diferentes empresas, oferecendo variados serviços. Esses jovens sintetizam, com suas histórias de vida e com as atividades laborais realizadas, o perfil do trabalhador que se desenha e que se alastra, neste século XXI, em todos os quadrantes do mundo. Tratam-se de trabalhadores acionados por intermédio de aplicativos diversos, sem quaisquer seguros ou regulação contratual formal, exercendo atividades marcadas por extensas jornadas de trabalho, esforço intenso e desgastante (Rafael relata pedalar aproximadamente $50 \mathrm{~km}$ todos os dias), baixa remuneração e por toda a sorte de instabilidades e inseguranças.

Além dos casos supramencionados, podem se tornar MEIs uma ampla variedade de trabalhadores, com destaque para os motoristas de aplicativo, categoria para a qual existe um chamado especial na página eletrônica do Portal do Empreendedor, onde se pode visualizar, em destaque,

${ }^{5}$ Referimo-nos à Lei Complementar nº. 128, de 19 de dezembro de 2008. 
o seguinte informativo: "Motorista de aplicativo, agora você pode se formalizar como MEI" (PORTAL DO EMPREENDEDOR, 2019).

Como demonstramos, em 2005 e, posteriormente, em 2008, surgiram legislações importantes para entendermos o estabelecimento das formas de trabalho autônomo no Brasil. Em 2017, um novo marco legislativo vem à tona, complexificando ainda mais essa situação. Nesse sentido, cabe fazer menção às prescrições estabelecidas pela reforma trabalhista, no que tange aos trabalhadores autônomos. Em seu artigo 442-B, podemos encontrar o seguinte texto:

A contratação do autônomo, cumpridas por este todas as formalidades legais, com ou sem exclusividade, de forma contínua ou não, afasta a qualidade de empregado prevista no art. $3^{\circ}$ desta Consolidação (BRASIL, 2017).

Basicamente, o que a legislação apresenta é, basicamente, um conjunto de prescrições que impossibilitam a caracterização dos trabalhos autônomos em relações de emprego, ao sabor dos desejos mais verossímeis do capital. Em poucas palavras, a legislação se ergue para regularizar a fraude!

O discurso da autonomia do trabalhador quer conduzir a ideia de que o sujeito é livre para escolher as relações de trabalho nas quais deseja se inserir. Mas, na realidade, sabemos que a liberdade deve implicar a possibilidade de eleição concreta, entre alternativas também concretas. Pelo exposto, não é isso que ocorre com os trabalhadores autônomos e, em especial, os pejotizados, os quais optam pela fuga ou pela tentativa de saída do desemprego quando necessitam se vincular a essa modalidade de trabalho.

Destarte, a figura do trabalhador denominado como "autônomo" deverá significar a expansão dessa forma flexível e precarizada de inserção sociolaboral e, assim como as outras formas - e muitas vezes articuladas com elas -, mostra-se extremamente desfavorável a todos aqueles que necessitam vender sua força de trabalho para sobreviver.

\section{Considerações finais}

Ao longo deste texto, procuramos demonstrar que, a partir da contrarreforma trabalhista implementada na realidade brasileira, ocorreu uma alteração de vulto no âmbito dos padrões trabalhistas até então estabelecidos, sobretudo mediante a regulamentação de modalidades contratuais precárias, como os trabalhos intermitente, terceirizado (para atividades fins) e autônomo, formas de inserção laboral que corroboram fortemente para provocar a degradação das condições de vida e existência de um expressivo contingente de trabalhadores.

Nesse sentido, a atual reforma trabalhista, ao contrário dos discursos e das promessas estabelecidas, teve como real propósito: ampliar a margem de manipulação do empresariado no modo e na forma como o trabalho passa a ser regulado no Brasil, assim como nos tipos de relações sociolaborais construídas entre as distintas frações de classe.

Isso implica atestar uma mudança histórica no nível de precarização do trabalho no Brasil e, como corolário, na degradação da classe trabalhadora, submetida cada vez mais a situações de pauperização absoluta. As novas modalidades de contratação da força de trabalho se expandem progressivamente, operando de modo articulado para oferecer aos setores dominantes, múltiplas formas de exploração com vistas à valorização do valor.

Esse processo ocorre com amplo e irrestrito respaldo do Estado que, sob o discurso da "modernidade", legaliza formas deletérias de trabalho, ao mesmo tempo em que estabelece bloqueios 
às formas de fiscalização e punição às irregularidades registradas no universo trabalhista brasileiro. Mais uma vez - e vividamente - o Estado expõe o seu caráter de classe e expressa o seu empenho em atender as requisições dos setores dominantes da sociedade brasileira.

Contudo, é preciso não perder de vista que, mesmo no quadro dessas possibilidades de contratação flexível e precária, no âmbito da institucionalidade, os setores dominantes continuam tendo à sua disposição o recurso à ilegalidade, expressa nas formas de trabalho informais e ilícitas.

Assim, a atual contrarreforma trabalhista marca mais uma ação restauradora do conjunto das forças dominantes brasileiras, articuladas com o propósito de impedirem que as mudanças sociais se operem "de baixo para cima", reatualizando as marcas de nossa formação social, na qual as revoluções "pelo alto" sempre se fizeram presentes, desconsiderando os interesses e anseios da maioria da população, como elucida Florestan Fernandes (2005).

Diante desse contexto, a precarização do trabalho se escancara e ganha contornos complexos nessa sociedade e a ausência de futuridade se mostra abertamente, sobretudo para uma parcela de jovens trabalhadores que, como concluiu Ricardo Antunes (2018), inspirado em Albert Camus: se contarem com a sorte, terão o privilégio da servidão. Reverter este quadro é uma tarefa para todos aqueles que lutam por outra forma de sociabilidade, pela auto-determinação do trabalho.

\section{Referências}

ABILIO, L. Uberização do trabalho: subsunção real daviração. 2017. Disponível em: https:// blogdaboitempo.com.br/2017/02/22/uberizacao-do-trabalho-subsuncao-real-da-viracao/. Acesso em: 06 out. 2019.

AGÊNCIA BRASIL. Brasil teve $2^{\circ}$ melhor desempenho em empreendedorismo em 2018. 2019. Disponível em: http://agenciabrasil.ebc.com.br/economia/noticia/2019-02/brasil-teve-2o-melhordesempenho-em-empreendedorismo-em-2018. Acesso em: 15 set. 2019.

ALVARENGA, D. País já tem 8,1 milhões de microempreendedores formais; veja atividades em alta entre MEIs. 2019. In: Portal G1. Disponível em: https://g1.globo.com/economia/noticia/2019/04/03/pais-jatem-81-milhoes-de-microempreendedores-formais-veja-atividades-em-alta-entre-meis.ghtml. Acesso em: 16 set. 2019.

ALVES, G. Terceirização: o futuro do trabalho no Brasil. In: Trab. Educ. Saúde, Rio de Janeiro, v. 15 n. 2, p. 337-345, maio/ago. 2017.

ANTUNES, R. O privilégio da servidão: o novo proletariado de serviços na era digital. São Paulo: Boitempo, 2018.

ANTUNES, R. Os sentidos do trabalho: ensaio sobre a afirmação e a negação do trabalho. São Paulo: Boitempo, 2009.

ANTUNES, R. DRUCK, G. A terceirização sem limites: a precarização do trabalho como regra. In: Revista O Social em Questão. Ano 18, n. 34-jul.-dez./2015.

ANTUNES, R. PRAUN, L. A sociedade dos adoecimentos no trabalho. In: Serv. Soc. Soc., São Paulo, n. 123, p. 407-427, jul./set. 2015.

BARBOSA, A. F. A formação do mercado de trabalho no Brasil. São Paulo: Alameda, 2008.

BEHRING, E. Brasil em contra-reforma: desestruturação do Estado e perda de direitos. São Paulo: Cortez, 2003. 
BRASIL. Lei no 13.429, de 31 de março de 2017. Altera dispositivos da Lei no 6.019, de 3 de janeiro de 1974, que dispõe sobre o trabalho temporário nas empresas urbanas e dá outras providências; e dispõe sobre as relações de trabalho na empresa de prestação de serviços a terceiros. Presidência da República. Casa Civil. Subchefia para Assuntos Jurídicos. Brasília, 31 de março de 2017a.

BRASIL. Lei no 13.467, de 13 de julho de 2017. Altera a Consolidação das Leis do Trabalho (CLT), aprovada pelo Decreto-Lei $n^{\circ}$ 5.452, de $1^{\circ}$ de maio de 1943, e as Leis $n^{\circ} \mathrm{s}$ 6.019, de 3 de janeiro de 1974, 8.036, de 11 de maio de 1990, e 8.212, de 24 de julho de 1991, a fim de adequar a legislação às novas relações de trabalho. Presidência da República. Casa Civil. Subchefia para Assuntos Jurídicos. Brasília, 13 de julho de $2017 b$.

BRASIL. Lei no 11.196, de 21 de novembro de 2005. Institui o Regime Especial de Tributação para a Plataforma de Exportação de Serviços de Tecnologia da Informação -REPES, o Regime Especial de Aquisição de Bens de Capital para Empresas Exportadoras -RECAP e o Programa de Inclusão Digital e da outras providências. Presidência da República. Casa Civil. Subchefia para Assuntos Jurídicos. Brasília, 21 de novembro de 2005.

BRASIL. Lei Complementar n⿳⼈ㅗㄹ 128, de 19 de dezembro de 2008. Altera a Lei Complementar no 123, de 14 de dezembro de 2006, altera as Leis nos 8.212, de 24 de julho de 1991, 8.213, de 24 de julho de 1991, 10.406, de 10 de janeiro de 2002 -Código Civil, 8.029, de 12 de abril de 1990, e dá outras providências. Presidência da República. Casa Civil. Subchefia para Assuntos Jurídicos. Brasília, 19 de dezembro de 2008.

CHAN, J; PUN, N; SELDEN, M. A política da produção global: Apple, Foxconn e a nova classe trabalhadora chinesa. In: ANTUNES, R. (Org.). Riqueza e Miséria do Trabalho no Brasil IV. São Paulo: Boitempo, 2019 .

DAL ROSSO, S. 0 ardil da flexibilidade: os trabalhadores e a teoria do valor. São Paulo: Boitempo, 2017.

DIEESE. Terceirização e precarização das condições de trabalho. 2017. Disponível em: https://www. dieese.org.br/notatecnica/2017/notaTec172Terceirizacao.pdf. Acesso em: 12 set. 2019.

DRUCK, G. Entrevista. 2017. Disponível em: https://apufpr.org.br/andes-sn-entrevista-graca-drucksobre-os-impactos-da-terceirizacao-no-pais/. Acesso em: 15 set. 2019.

DUVIVIER, G. 1 Vídeo (18:21 min.). Emprecariado. Publicado pelo HBO. 2017. Disponível em: https:// www.youtube.com/watch?v=Y9V8fyvt_9g. Acesso em: 10 ago. 2019.

FERNANDES, F. O que é revolução? In: PRADO JÚNIOR, Caio. FERNANDES, Florestan. Clássicos sobre a revolução Brasileira. São Paulo: Expressão Popular, 2005.

FILGUEIRAS, V. A. As promessas da Reforma Trabalhista: combate ao desemprego e redução da informalidade. In: KEIN, D; OLIVEIRA, R. V; FILGUEIRAS, V. A. (Orgs.). Reforma trabalhista no Brasil: promessas e realidade. Campinas, SP: Curt Nimuendajú, 2019.

FILGUEIRAS, V. A. BISPO, B. COUTINHO, P. A reforma trabalhista como reforço a tendências recentes no mercado de trabalho. In: KREIN, D; GIMENEZ, D. M; SANTOS, A. L. (Orgs.). Dimensões críticas da reforma trabalhista no Brasil. Campinas, SP: Curt Nimuendajú, 2018.

FONSECA, V. P. TERCEIRIZAR ATIVIDADE-FIM É ALUGAR TRABALHADOR. In: CAMPOS, A. G. (Org.). Terceirização do trabalho no Brasil: novas e distintas perspectivas para o debate. Brasília: Ipea, 2018. 
GEM. Empreendedorismo no Brasil: relatório executivo 2016. Coordenação de Simara Maria de Souza Silveira Greco; diversos autores. Curitiba: IBQP, 2017. Disponível em: http://www.sebrae.com.br/ Sebrae/Portal\%20Sebrae/Anexos/GEM\%20Nacional\%20-\%20web.pdf. Acesso em: 01. set. 2019.

GEM. Empreendedorismo no Brasil: relatório executivo 2018. Coordenação de Simara Maria de Souza Silveira Greco; diversos autores. Curitiba: IBQP, 2019. Disponível em: https://datasebrae.com.br/wpcontent/uploads/2019/02/Relat\%C3\%B3rio-Executivo-Brasil-2018-v3-web.pdf. Acesso em: 01 set. 2019.

GOUNET, T. Fordismo e Toyotismo na civilização do automóvel. São Paulo: Boitempo, 1999.

HERNÁNDEZ, J. G. Crítica a la frexiseguridad.Disponível em: https://www.sciencedirect.com/ science/article/pii/S1870467013719638?via\%3Dihub. Acesso em: 04 mar. 2019.

IANNI, O. 1989. A questão social. In: Revista USP. Disponível em: http://www.revistas.usp.br/revusp/ article/view/25490. Acesso em: 06 mar. 2019.

KEIN, D; OLIVEIRA, R. V. Para além do discurso: impactos efetivos da Reforma nas formas de contratação In: KEIN, D; OLIVEIRA, R. V; FILGUEIRAS, V. A. (Orgs.). Reforma trabalhista no Brasil: promessas e realidade. Campinas, SP: Curt Nimuendajú, 2019.

KREIN, D; ABILIO, L. et al. Flexibilização das relações de trabalho: insegurança para os trabalhadores. In: KREIN, D; GIMENEZ, D. M; SANTOS, A. L. (Orgs.). Dimensões críticas da reforma trabalhista no Brasil. Campinas, SP: Curt Nimuendajú, 2018.

LAVILLE, C; DIONNE, J. A construção do saber: manual de metodologia da pesquisa em ciências humanas. Belo Horizonte: Editora da UFMG, 1999.

MAEDA, P. Contrato zero-hora e seu potencialprecarizante. In: ANTUNES, R. (Org.). Riqueza e Miséria do Trabalho no Brasil IV. São Paulo: Boitempo, 2019.

MARTELLO, A. Nova lei trabalhista deve gerar mais de 6 milhões de empregos, diz Meirelles. 2017. In: Portal G1. Disponível em: https://g1.globo.com/economia/noticia/nova-lei-trabalhista-vai-gerarmais-de-6-milhoes-de-empregos-diz-meirelles.ghtml. Acesso em:10 set. 2019.

MARTINS, S. P. Direito do Trabalho. São Paulo: Atlas, 2003.

MOTA, A. E. Cultura da crise e seguridade social. São Paulo: Cortez, 2015.

NAVARRO, V. LOURENÇO, E. (Orgs.). O avesso do trabalho IV: terceirização, precarização e adoecimento no mundo do trabalho. São Paulo: Expressão Popular, 2017.

OIT. Perspectivas sociales y del empleo en el mundo -Tendencias 2017. Disponível em: https:// www.ilo.org/wcmsp5/groups/public/---dgreports/---dcomm/---publ/documents/publication/ wcms_540901.pdf. Acesso em: 04 mar. 2019.

PARECER DA REFORMA. (2017). Voto do Relator, Dep. Rogério Marinho. Comissão Especial destinada a proferir parecer ao Projeto de Lei $n^{\circ}$ 6.787, de 2016, do Poder Executivo que "altera o Decreto-Lei $n^{\circ}$ 5.452, de 1ํ de maio de 1943”. Brasília: Câmara dos Deputados. Disponível em: https://www.camara.leg. br/proposicoesWeb/prop_mostrarintegra? Codteor=1544961. Acesso em: 10 ago. 2019.

PELATIERI, P. CAMARGOS, R. C et al.TERCEIRIZAÇÃO E PRECARIZAÇÃO DAS CONDIÇÕES DE TRABALHO: CONDIÇÕES DE TRABALHO E REMUNERAÇÃO EM ATIVIDADES TIPICAMENTE TERCEIRIZADAS E CONTRATANTES. In: CAMPOS, A. G. (Org.). Terceirização do trabalho no Brasil: novas e distintas perspectivas para o debate. Brasília: Ipea, 2018.

PINTO, G. A. A organização do trabalho no século XX. São Paulo: Expressão Popular, 2010. 
PORTAL DO EMPREENDEDOR. Estatísticas. 2019. Disponível em: http://www.portaldoempreendedor. gov.br/estatisticas. Acesso em: 16 set. 2019.

SILVA, A. M. A precarização do trabalho docente no século XXI:o precariado professoral e o professorado estável formal sob a lógica privatista empresarial nas redes públicas brasileiras. Tese (doutorado) -Universidade Federal do Rio de Janeiro, Faculdade de Educação, Programa de Pós Graduação em Educação, 2018. 395p.

SOEIRO, J. A formação do precariado: transformações no trabalho e mobilizações de precários em Portugal. Coimbra, 2015. Tese de doutoramento. Disponível em: <http://hdl.handle.net/10316/28406>. Acesso em: 04 mar. 2019.

TAVARES, M. A. Os fios (in)visíveis da produção capitalista: informalidade e precarização do trabalho. São Paulo: Cortez, 2004.

TAVARES, M. A. Empreendedorismo e expropriação da subjetividade. In: BOSCHETTI, I. (Org.). Expropriação e direitos no capitalismo. São Paulo: Cortez, 2018.

TEIXEIRA, M. A reforma trabalhista e as mulheres. In: TEIXEIRA, M. GALVÃO, A. et al. (Orgs.).

Contribuição crítica à reforma trabalhista. Campinas, SP: UNICAMP/IE/CESIT, 2017.

TRINDADE, H. O precariado no Brasil Contemporâneo. Tese (Doutorado em Serviço Social). Programa de Pós-Graduação em Serviço Social. Universidade Federal do Rio de Janeiro. Rio de Janeiro, 2019, 249p.

TRINDADE, H. A contrarreforma trabalhista no Brasil e o precariado: contribuição ao debate. In: Revista Jurídica Trabalho e Desenvolvimento Humano, v. 3, 9 jun. 2020.

TST. Ranking dos Assuntos mais Recorrentes nas Varas. 2019. Disponível em: http://www.tst.jus. br/web/estatistica/vt/assuntos-mais-recorrentes. Acesso em: 16 set. 2019. 